\title{
Гусейнова И.И.,
}

старший преподаватель Университета кооперации,

Азербайджан, г. Баку,

e-mail: huseynova.irada.62@mail.ru

\section{АНААИЗ СЕМАНТИЧЕСКОЙ УНИВЕРСААЬНОСТИ И УНИКААЬНОСТИ ФРАЗЕОАОГИЧЕСКИХ ЕАИНИЦ В ЯЗЫКЕ АХМЕАА ХАМАИ ТАНПЫНАРА}

В статье в аспекте универсальности и уникальности анализируются особенности фразеологизмов, используемых в произведениях А.Танпынара, известного умением пользоваться в своем творчестве кингвистическими единицами с особым мастерством. Существование противоречивых фактов в использовании фразеологизмов в языке автора, имеющих особый вес - уделение места утратившим функциональность лексемам наряду с единицами, активно используемыми на современном уровне языка - относится к тем факторам, показывающим актуальность лингвистического исследования произведений А. Танпынара.

Если некоторые из этих фразеологизмов преАставляют особый интерес как носители национальных и этических факторов и структурно, и семантически, то Аругая часть вызывает интерес соответствием с встречающимся в различных языках фразеологизмами. Подобный анализ фразеилогизмов, используемых в художественных произведениях, также позволяет наблюдать особенности их формирования и функциональности в языке. Аингвистический анализ произведений А.Танпынара показывает, что в целом, универсальность фразеологических единиц может быть связана с происхождением языков исторически из одного источника или же с заимствованиями в языке, являющимися результатом взаимного контакта с Аругими языками. Эти оба явления выступают причиной универсальности фразеологизмов в языке произведений автора. Уникальность фразеологических единиц может быть обусловлена как мингвистическими, так и экстралингвистическими факторами. Поскольку все факты, связанные с образом мышления и жизни народа, находятся в основе фразеологической единицы, а также в силу воздействия социальных факторов на тенденции развития языка, в каждом языке естественно существование уникальных фразеологизмов, примечательно Аля каждого языка.

Кмючевые слова: Ахмет Хамди Танпинар, топоним, культурная коннотация, семантический анализ.

\author{
Huseynova Irada Isa gizi, \\ senior lecturer of University of Cooperation, \\ Azerbaijan, Baku, e-mail: huseynova.irada.62@mail.ru \\ Analysis of semantic universality and uniqueness of phraseological units \\ in the language of Ahmad Hamdi Tanpinar
}

In the article the universal and uniqueness peculiarities of the phraseological units in A.Tanpinar's works drawing attention with the manifestation of the ability to use language units in the creativity with a particular skill are analyzed. The coincidence of contradictory facts in the development of frazeologisms, which have the particular interest in the language of the author, is the fact that, in addition to the functional units of modern language, lexemes that have lost their functionality and it is one of the factors that demonstrate the relevance of linguistic investigation of Tanpinar's works. Though some of these frazeologisms are of particular interest as bearer of national and ethical factors, both in terms of their structural and semantic views, while the other ones are interested in conformity with the frazeologisms found in different languages. Analyzing the frazeologisms used in the artistic works in this way also allows them to observe their peculiarities of forming and functionality in the language. The linguistic analysis of Tanpınar's works shows that the universality in phrazeological units can usually be related to the origin of language from the same source or to the acquisition of traces of mutual contact with other languages historically. Both cases are justified as the cause of the universality of frazeologisms used in the author's works. Uniqueness in the phrazeological units can be formed by both linguistic and extra-linguistic factors. As all the facts about the way of life and the way of thinking are based on the phrazeological unit, 
as well as the social factors affect the development tendencies of the language, the existence of frazeologisms is remarkable in every language.

Key words: Ahmet Hamdi Tanpinar, toponym, lexicon, cultural connotation, semantic analysis.

\author{
Гусейнова И.И., \\ Кооперация университетінің аға оқытушысы, \\ Азербайжан, Баку к., e-mail: huseynova.irada.62@mail.ru

\section{Ахмед Хамди Танпынар тіліндегі фразеологиямық бірліктердің семантикалық әмбебаптығын және бірегейлігін талдау}

\begin{abstract}
А. Танпынар өз шығармаларында тілдік бірліктерді аса шеберлікпен пайдаяана алатындығымен ерекшеленеді. Мақалада ол қолданған фразеологиялық бірліктердің әмбебаптығы және бірегейлігі әңгімеленеді. Қазіргі тілде көп қолданылатын фразеологизмдермен қатар бұрынғы қызметін жоғалтқан фразеологизмдерді іске қосып жандандыруы. А. Танпынар шығармаларының мингвистикалық тұрғыдан аса құндылығын көрсетеді.

Ахмед Хамди қолданған фразеологизмлер мазмұны, құрылымы жағынан ұлттық сипаты болуымен қатар, өзге түркі тілдерінде ұшырасатындығымен қызықтырады. Жазушы шығармамарындағы фразеологизмдерді талдау олардың пайда болу тарихын бікуге де көмектеседі. Фразеологизмдердің бір бөлегі бір түпкітектен шыққан болса, енді бір бөлегі өзге түркі тілдерінен ауысуы мүмкін. Осы жағдай автордың фразеологизмдерді қолдануының бірегейлігін көрсетеді. Әр халықтың өмір сүру салтына, ойлау қабілетіне байланысты пайда болған фразеологизмдер өзінің бірегейлігімен көзге түседі. Тілдің дамуына әлеуметтік факторлардың үлкен ықпалы болғандығы да байқалады.
\end{abstract}

Түйін сөздер: Ахмет Хамди Танпынар, топоним, мәдени коннотация, семантикалық та^дау.

\section{Введение}

Один из видных и уважаемых представителей турецкой литературы XX века Ахмед Хамди Танпынар является мастером слова, привлекающим внимание образом мышления, философским подходом к событиям, чутким отношением к изменениям, порожденным в тюркском народе и в его сознании, отличающимися взглядами, вызванными соединением восточной и западной культур, вместе с тем, умением мастерски пользоваться в своих работах богатством тюркского языка. Язык автора, наряду с отображением происходивших в периоды творческой деятельности изменений в языке, характеризуется и мастерским использованием различных лексических пластов языка писателем, глубоко сведущим в таких областях искусства, как музыка, живопись. Это особенно заметно использованием в языке Ахмеда Хамди Танпынара фразеологизмов.

\section{Эксперимент}

При изучении языка с различных аспектов уделение внимания человеческому фактору как носителю языка, необходимо прояснения вопросов связи языка и мышления.

Некоторые языковые категории выделяются теснотой этой связи и более наглядным отобра- жением в лингвистических единицах. Фразеологические единицы, составляющие особый пласт словарного запаса языка, являются одним из наиболее ярких элементов этнокультуры и психолингвистики народа.

Фразеологические единицы представляют собой особую лексическую группу, которая отображает человеческую психологию - косвенным образом образ мышления, мировоззрение, образ жизни, национально-духовные ценности, сведения об эмоциональной характеристике народа. Наличие метафорического иносказания в семантике компонентов этой группы слов приводит к ослаблению дифференциальной семы и возникновению тенденции отдаления от конкретного содержания.

Этот аспект оценки явлений с различных сторон обуславливает появление конновативных нюансов в содержании фразеологического соединения, что в некоторых случаях в зависимости от контекста отражается в форме наблюдения окказионального изменения и осмысления. Это связано с тем, что стиль писателя, возможность использования его языковых единиц, а также влияние художественной литературы на развитие конкретного языка отражаются на языке литературных произведений и представляют собой проблему, ожидающую своего решения. В этом смысле и произведения Ахмеда Хамди Танпынара представляют особый интерес как художе- 
ственный источник активной функциональности фразеологических единиц.

Поскольку фразеологизмы являются лексическими единицами, отражающими национальное сознание и мировоззрение, их семантический и функциональный анализ помогает выявить ряд универсальных и уникальных моментов. Наличие национальных особенностей - уникальных черт во фразеологизмах, отражающих взгляды людей, их мышление, мировоззрение и национально-эстетические взгляды, является неизбежным фактом. Подобные характерные элементы, делающие определенный язык и культуру неповторимыми, отличающие его от других, вызывают особый интерес в качестве смысловых компонентов фразеологических единиц. Такие выражения, в которых отражены и вера и верования народа, представляют собой факторы, играющие ключевую роль в изучении различных культур. Обладая иносказательным смысловым содержанием, носящие устоявшийся метафорический характер фразеологизмы особенно ценны с точки зрения сохранения обычаев народа, связанных с богатым историческим опытом и традициями, трудовой деятельностью и образом жизни. При подобном подходе изучение лексических единиц, принадлежащих к разным языкам, позволяет выявить отличающееся мировоззрение и образ мышления народовносителей этого языка. При подходе именно в этом контексте понимание указанных лексических единиц обуславливает наличие сведений об исторических, этнографических, культурных явлениях.

Перевод подобных лакунарных единиц обычно сопровождается появлением определенных проблем. Если принять во внимание связь с человеческим мышлением и логикой в целом образования фразеологизмов, как и других единиц, то с легкостью можно объяснить обращающую на себя внимание универсальность в существующих в различных языках фразеологизмах. В отображающих в себе общечеловеческие ценности фразеологических единицах преобладание фактора универсальности встречается чаще.

Исследование универсальности во фразеологизмах в конечном итоге приводит к появлению ряда общих закономерностей. В первую очередь, универсальность фразеологизмов обуславливается закономерностями аналитического и логического мышления: «Фразеология выступает как самобытный языковый универсалий: в моменты выступления языка как коммуникативного средства его функциональность не может не привести к образованию стабильного словарного комплекса» (Royzenson, 1973: 78). Основное качество фразеологизмов как единиц языка состоит в том, что вне зависимости от семантики компонентов, выражение ими единого значения может быть охарактеризовано как универсальный фактор. Идентичное осмысление фразеологизмов, относящихся к различным языкам, основывается на образное сравнение и связь метафорических взглядов с общими представлениями. Универсальность проявляется и в семантических, и в структурных особенностях. Ю.Сологуб связывает возникновение фактора универсальности во фразеологизмах с двумя главными условиями: лингвистическими универсалиями и универсалиями образа жизни, жизни человека (Solodub, 1990: 35). Во втором случае универсальные особенности, будучи связаны с объективным миром, выражают признаки, отражающие существование человека как биологического и социального индивидуума. Присущие различным языкам лексические единицы объединяют в себе и элементы, присущие конкретному языку, и появивщиеся как отражение лексических связей. Представить универсальные элементы за пределами специфических особенностей развития языка тоже невозможно. Именно в результате подобного неправильного взгляда становимся порой свидетелями отношения к носящим универсальный характер фразеологизмам как к заимствованным лингвистическим фактам.

Другой важный вопрос заключается в том, что обладающие универсальным характером лингвистические элементы к тому же обращают на себя внимание уникальными и носящими отличающийся характер структурными и семантическими чертами. Следовательно, говоря о факторе универсальности лексическая единица должна быть всесторонне проанализирована, представляющие его отличающиеся стороны нюансы будучи проакцентированы, учтены.

«Во внутреннем содержании фразеологические единицы хранят нравственные законы, здоровое мышление, которые хотят передать в кратком виде предки последующим поколениям» (Maslova, 2004: 45). Носящие следы национальной культуры фразеологизмы, образно отображая представления о мире, неся национальный колорит, кроме прочего, обладают национальнокультурными коннотативными элементами. В этом смысле непреложна роль фразеологизмов в формировании и передаче национального взгляда, мировоззрения. Говоря словами А.Бабкина, 
во фразеологизмах «отражаются дух и самобытность народа» (Babkin, 1977: 7).

Используемые в произведениях Танпынара фразеологизмы обращают на себя внимание с точки зрения обладания отрицательного или положительного содержания. Практика показывает, что в целом, во всех языках фразеологизмы, преимущественно, возникли из-за выражения отрицательных событий, чувств и ощущений. Данный факт можно отнести к универсальным тенденциям, связанным с фразеологизмами.

Фразеологизмы, привлекающее к себе внимание в качестве особого пласта в языке произведений Танпынара, естественным образом смешиваются с текстом, выступают показателем национального колорита, а в некоторых моментах - и заимствованных форм в языке.

«Глубокое изучение фразеологии какоголибо национального языка» составляет «основное звено в усвоении этого языка и также окно в богатый, разноцветный и немного таинственный мир носителей того языка» (Mirzaliyeva, 2009:25).

«Мастера слова, наряду с использованием идущих из глубин истории слов и выражений, и сами внося в язык индивидуальные манеры выражения, обновляют его и таким образом вносят свой вклад в литературный язык эпохи, в котором жили и творили» (Mammadov, 2005: 117).

Е.Н.Калиткина обратила внимание на то, что использование слова «орел» о «герое, красивом, сильном человеке», лексемы «сокол» об «отличающемся доблестью, привлекательностью и буйным нравом мужчине или же юноше», 3оонима «медведь» о «неприглядном, грубом» человеке, слова «лис» о «коварном человеке» при характеристике обладает определенным универсализмом (Kalitkina, 2011: 7).

Принимая во внимание то, что фразеологизмы когнитивно охватывают более сложный процесс, и то что порой при их использовании актуализируются компоненты соедиения (Cheyf, 1975: 23), эти лексические единицы как представители межкультурной коммуникации, создают условия «для формирования национально-культурной идентичности носителя языка - народа (Teliya, 1999: 14). Характеристика национального сознания во фразеологизмах проявляется на уровне коннотации.

Для выражения сильного дождя в азербайджанском языке применяется идиома «tut ucundan, göyə ç1х» - «бери за конец, взберись на небо». В качестве аналога этого в немецком языке используется вариант «еs regnet in Strömen, es regnet Bindfäden//Strippen» - «дождь льется словно веревка» (Binovich, 1995: 643), в английском языке - «it is raining cats and dogs» - «с дождем льются собаки да кошки», в русском языке - «дождь льет как из ведра», что стало возможным в результате развития образного мышления, представлениях народа о коннотативном значении. Как отмечал и В.Маслов, специфические черты каждого языка могут быть объяснены национально-культурной коннотацией, наличием символов и стереотипов (Maslova, 2004: 71).

Во фразеологизмах универсальность, в первую очередь, может быть объяснена обладанием людьми общими в эмоциональном плане качествами. Кроме этого, хотя люди живут в разных условиях, жизненный опыт во многие моменты завершается обретением одинакового логического результата: «bir əldə iki qarpız tutma» - удержание в одной руки двух арбузов, - «за двумя зайцами погонишься, ни одного не поймаешь» (русский язык)// wer zwei Hasen hetzt, fängt keinen (немецкий язык)// if you run after two hares, you will catch neither (английский язык) (побежишь за двумя зайцами, не поймаешь ни одного). В этих семантически универсальных единицах основное значение заключается в недостижении имеющим две цели ни одной из них. Однако с точки зрения стиля выражения, предмета сравнения проявляются определенные различия, что может быть объяснено этнокультурными факторами - возникают новые формы выражения на основе универсального образа. Принимая этот образец во внимание, можно утверждать, что показатели уникальности во фразеологизмах обратно пропорциональны степени сохранения этнокультурных признаков и факторам универсальности: степень универсальности выражения ограничивает возможности выступления в качестве культурного символа, присущего конкретному народу.

Используемые в произведениях Ахмеда Хамди Танпынара фразеологические единицы вызывают интерес и в качестве источника для заполучения определенных представлений о фразеологической системе тюркского языка в целом. «... sahiden güzel, aşkolsun!» - «....и вправду красив, будь оно не ладно» («Мелодия махур»). Такие выражения, как geçmiş olsun соболезную (в прямом смысле - пусть останется в прошлом), ellerine sağlik - спасибо (в прямом смысле - здоровье вашим рукам), ziyade olsun (в прямом смысле - пусть будет в достатке), sağl1k olsun (пусть будет здоровье), kolay gelsin (пусть будет легко), sizlere ömür - соболезную (в пря- 
мом смысле - вам долгой жизни), söz kesmek сговорится (в прямом смысле - порезать слово) и т.д. без специального разъяснения представляют собой труднопереводимые единицы, отражающие этнокультурные и психологические моменты. Выражение «ellerinden öperim» - «буду целовать твои руки» будучи выражением, обладающим особой традицией, ценностью и этическим весом, отражая совершенно отличные от западных традиций моменты, может расцениваться как несущее уникальный характер выражение. Правильное понимание подобного рода выражений обуславливает наличие сведений не только о языке, но и об образе мышления, ценностях, представлениях народа. Большинство используемых в произведениях Танпынара фразеологических единиц представляют собой носящие в этом виде уникальный характер единицы: Mümtaz'ın içi burkuldu - Сердие Myмтаза еркнуло. В источниках словосочетание іс̧і burkulmak растолковывается как - «печальное состояние», «обычно немного меланхолии, немного беспокойства, сожаления... может также использоваться, когда кто-то нервничает .... или ненавидит» (12).

En haklı olduğu yerde bile ăgzını açar açmaz herkesin «sen sus, böyle şeylere karışma!» der gibi baktı̆̆ bir adam için rütbenin, nişanın, hayatta muvaffakiyetin bir manasi olabilirmiydi? - Даже в том случае когда ты прав, не раскрыв рта, увидеть взгляд, говорящий что, заткнись, имеет ли смысл почет и звание? («Мелодия махур»). Выражение «ağzini açar açmaz» - «только раскрыв рот» хотя содержательно обладает определенным универсальным свойствам использования, выразительно может расцениваться как уникальный фразеологизм.

Сочетание «həvəsini almaq» - «успокоить свой пьл», которое встречается в произведении Танпынара «Мелодия махур», в этом контексте обратила на себя наше внимание: Hiçbir moda ve yenilik yoktu ki İsmail Molla'nın gelini herkesten önce ondan hevesini almış olmasın - Неm maкой моды или новшества, которую невестка Молль Исмаила прежде всех не испробовала бы. В азербайджанском языке в близком значении используются словосочетания «gözünün qurdunu öldürmək», «tarçı̆̆ını götürmək» и «tarçı̆̆ını almaq».

В других фразеологизмах обращают на себя внимание соответствие в определенном смысле компонентов по сравнению с азербайджанским языком: $O$ zaman, с̧осй̆unu azarliyan bir anne gibi, güzel başını sallıyarak kendi kendine: «babamın kanı uyanıyor», - diye düşünürdü - Tozда, как мать, крачащуая на своего ребенка, свесив красивую головку, приговаривая сама себе «пробуждается кровь моего отица», размышиляла».

Тайный концептуальный потенциал, устоявшийся в семантике фразеологических единиц, хранит в себе глубокие коннотативные значения. Фактор уникальности, подразумевающий наличие характерных для того или иного языка или языковой семьи особенностей, выражается образованием подобного типа коннотаций, отличающихся значений. Использование фразеологизма в процессе общения в действительности служит донесению информации о историко-культурном наследии в единице языка, мировоззрения. Встречающиеся в романе А.Танпынара «Покой» фразеологизмы, а также другие выражения, носящие все показатели фактора уникальности, преследуют цель донесения национального колорита до читателя, создания особого представления:

"Artı kimse geceleyin istemeden ettiyi gurultu için veya sabahleyin diyer pancurlar açllmadan evvel kendi odasının pancurlarını açtı̆̆ birbirinden özür dilemiyor, - Kusura bakmayın, sizi demin galiba rahatsı ettim!- diye söze başlıyacă̆ yerde sadece hal-hatır soruyordu» - «Никто уже не просит у другого прощения за шум поздней ночью или же к утру, или же за то, что открывал иторы в своей комнате, прежде чем открывать их в других комнатах, вместо того чтобы сказать - не обессудьте, кажется я вас вчера побеспокоил, приступает к речи простым приветствием». «ӧzür dilemek» - «просить прошение», «hal-hatır sormak» - «приветствовать» могут быть переведены на какой-либо язык, однако обращают на себя внимание в качестве носителей уникальных особенностей тонкие моменты внутри выражения, этнокультурные и психологические тонкости. Особенно недопустим буквальный перевод таких выражений, как «kusura bakmayın» - «не обессудьте» (в прямом смысле - не смотрите на погрешности).

Некоторые из фразеологизмов в произведении автора «Покой» обращают на себя внимание частичной универсальностью. Так, некоторые из них носят универсальность в своих компонентах - структурно, другие содержанием, которое выражают. "Tevfik Bey’in gelmesiyle iş büsbütün altüst oldu»- "С приходом Тевфик-бека все стало вверх-дном».

Выражение «alt-üst olmaq» - «верх-дном» относятся к лингвистическим единицам с меньшими изменениями присутствующими в разно- 
системных языках: You've managed to turn this village upside-down.// Вы перевернули эту деревню вверх дном. Haven't we turned that house upside-down at this point?// Разве мы еще не перевернули дом вверх дном?

На основе языкового корпуса возможно отслеживание во многих языках лексических единиц, а также фразеологизмов, наблюдение за частотой использования в различные периоды, тенденции развития. На основе являющейся одной из таких программ «Ngram Viewer» мы постарались рассмотреть особенности использования выражений «ирside-down» $u$ «вверx дном».

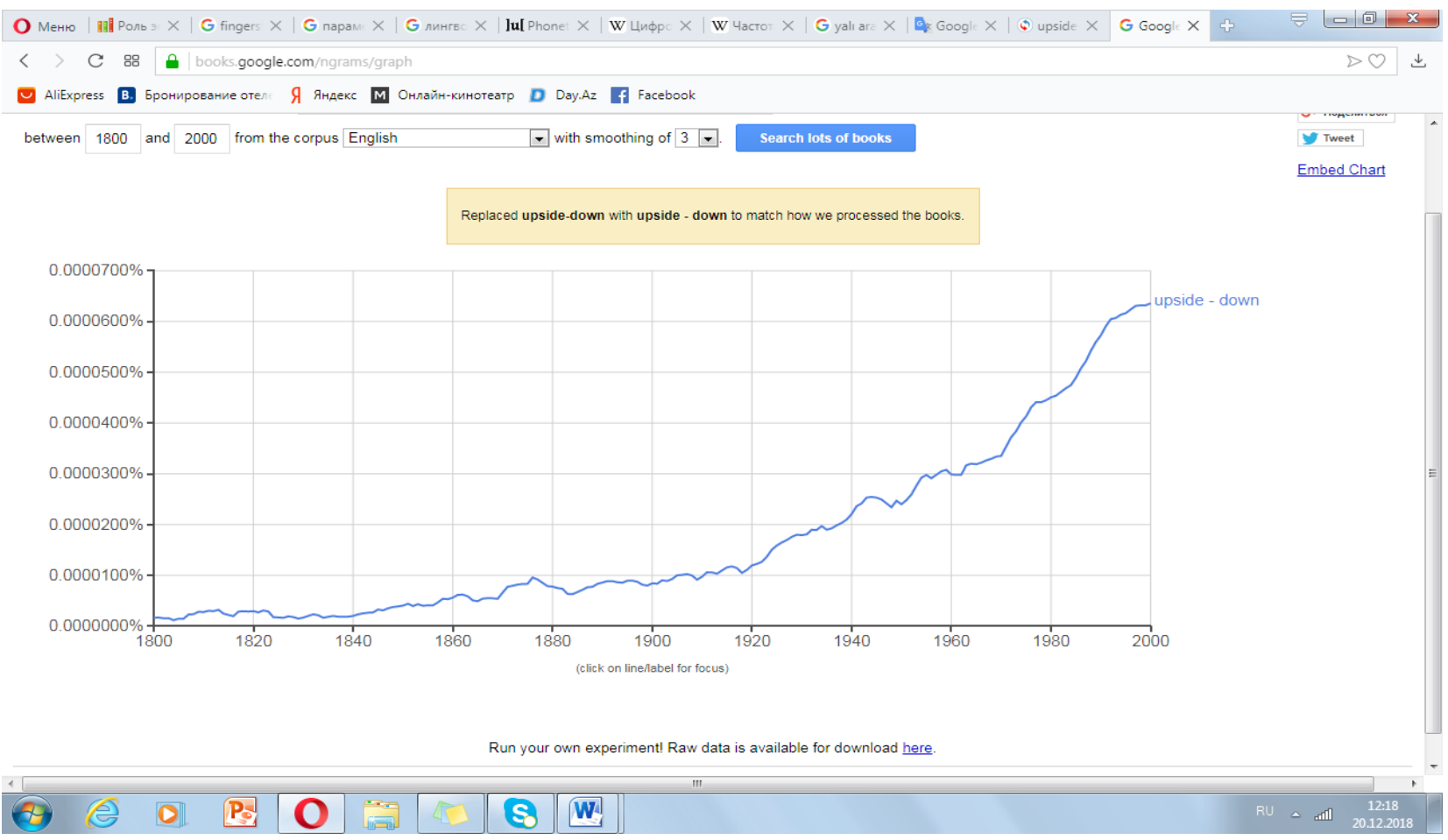

Как видно, на основе Национального коруса английского языка можно увидеть используемость выражения «upside-down» еще в 1800-ых годах, однако можно заметить обретение в 2000ые годы более высокой частоты использования.

Факты демонстрируют использование русского выражения «вверх дном» с начала XX века, достижения примерно с 1950-ых годов наивысшей частоты использования.

Универсалии подобного типа основываются на общность, универсальность человеческого сознания и логического мышления.

Рассмотрим другое предложение, используемое в произведении «Покой»: «Geri kalan zamanı da masa başıında tohumları ayırmak, Hollanda'ya, Italya'ya, Ingiltere'ye, hatta Amerika'ya kadar meşhur çiçekçi müesseselerine mektup yazmak, cevap vermek, konu komşudan kendi huylarını almış olanlara usul öyretmek doldururdu» - «Ocmaвmee- ся время заполнял сортировкой семян, писанием писем в известные иветоводческие предприятия вплоть до Голландии, Италии, Англии, даже Америки, ответами на пришедшие письма, изучением соседям средств».

Выражение «geri kalan zaman» - «оставщееся время» выражает смысл лишнего, свободного времени, иного времени. Любопытно, что в азербайджанском языке в смысле экономии и хранения на «черный» день используется выражение «geri atmaq» (в прямом смысле - бросить назад). Выражение «kendi huylarını almış olanlan» в этом предложении также вызывает интерес. Выражающее смысл «адаптироваться» данное сочетание в тюркском языке представляет группу обладающих одинаковой структурой лексических единиц типа «kendi hevâsina [arzûsuna] birakılan», используемых в тюркском языке и в современный период. 


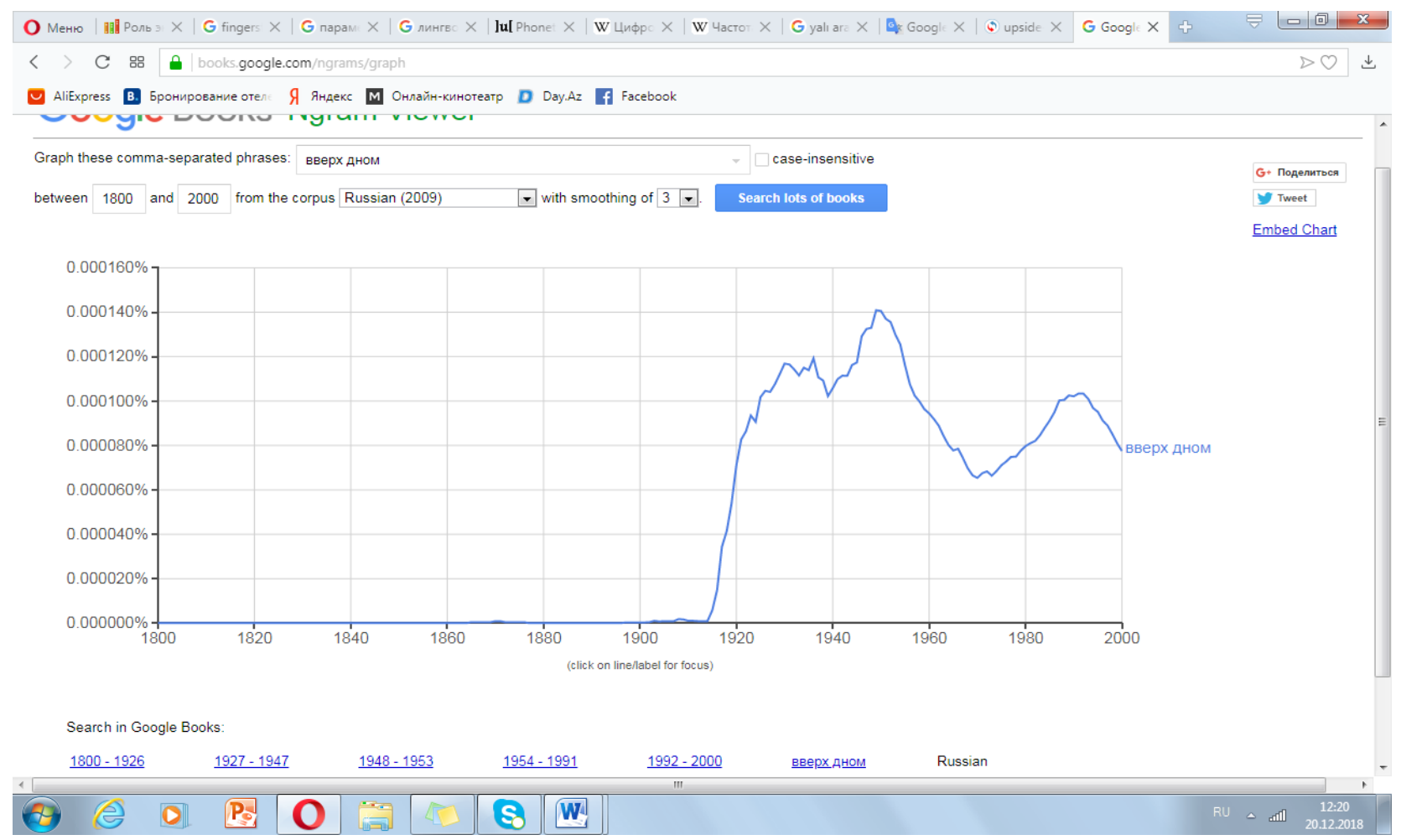

\section{Результаты и обсуждение}

Рассмотрение универсальных и уникальных качеств в лексических единицах даже в родственных языках завершается выявлением ряда отличительных моментов. Единица, использование которой в одном языке считается приемлемым, в другом языке может полагаться «грубым», даже неэтичным. Например, в тюркском языке слово «mirlldanmak» - «бубнить, напевать» используется в значении напевания человеком музыкального отрывка. Это выражение используется и в произведениях А.Танпынара: «Nuran balıktan yorulduğu zaman dayısının mirlldandiğı şarkı veya besteye iştirak ediyor, Tevfik Bey, yeyeninin kendisine yardıma geldiyini görünce sesini yükseltiyor, lüfer avı musıki safasına dönüyordu» - «Когда Нуран устает от рыбы, он участвует в песнях и композиииях, которые напевает его дядя, Тевфикбей, видя, что племянник идет на помощь, повышает голос, охота превращается в музыкальный праздник».

В азербайджанском языке использование данного выражения по отношению к людям не считается целесообразным.

\section{Заключение}

Рассматривание универсальных и уникальных качеств в лексических единицах даже в родственных языках завершается выявлением ряда отличающихся моментов. Единица, использование которой в одном языке считается приемлемым, в другом языке может полагаться «грубым», даже неэтичным. Например, в тюркском языке слово «mirldanmak» - «бубнить, напевать» используется в значении напевания человеком музыкального отрывка. Это выражение используется и в произведениях А.Танпынара: «Nuran balıktan yorulduğu zaman dayısının mirlldandığı şarkl veya besteye isstirak ediyor, Tevfik Bey, yeyeninin kendisine yardıma geldiyini görünce sesini yükseltiyor, lüfer avı musıki safasına dönüyordu» - «Когда Нуран устает от рыбы, он участвует в песнях и композищиях, которые напевает его дядя, Тевфикбей, видя, что племянник идет на помощьь, повышает голос, охота превращается в музыкальный праздник».

В азербайджанском языке использование данного выражения по отношению к людям не считается целесообразным. 
Универсальность во фразеологических единицах может быть связана с историческим формированием из одного и того же источника или же лингвистическими заимствованиями. Универсальность во фразеологических единицах может обуславливаться как лингвисти- ческими, так и экстралинвистическими факторами. Так, все факты, связанные с образом жизни и мышления народа в целом - традициями, верой и верованиями, историческими событиями - могут находиться в основе фразеологических единиц.

\section{Литература}

Ройзензон Л.И. Лекции по общей и русской фразеологии. Ч. І. - Самарканд, 1973. - 290 с.

Солодуб Ю.П. Национальная специфика и универсальные свойства фразеологии как объект лингвистического исследования // Филологические науки. - М: Наука, 1990. - № 6. - С. 35.

Маслова В.А. Лингвокультурология: Учеб. Пособие для студ.высш. учеб.заведений. - 2-е изд., стереотип. - М.: Издательский центр “Академия”, 2004. - 208 с.

Бабкин А.М. Идиоматика (фразеология) в языке и словаре // Современная русская лексикография: 1977 / отв. ред. А.М. Бабкин. - Л., 1979. - С. 4-19.

Мирзалиева М. Теоретические проблемы фразеологии тюркских языков. - Баку: Нурлан, 2009. - 296 с.

Мамедов М.Б. Филологические мысли. - Баку: Нурлан, 2005. - 230 с.

Калиткина Е.Н. Позитивное и негативное начало в анималистической характеристике антропонимов // Университетские чтения - 2011. Материалы научно-методических чтений ПГЛУ. - Часть VIII. - Пятигорск: ПГЛУ, 2011. - 158 с. - С. 25-30.

Чейф У.Л. Значение и структура языка. - М.: Прогресс, 1975. - 432 с.

Телия В.Н. Фразеология в контексте культуры [Текст] / В.Н. Телия. - М.: Языки русской культуры, 1999. - 337 с.

Бинович Л.Э. Немецко-русский фразеологический словарь [Текст] / Л.Э. Бинович. - М.: Аквариум, 1995. - 768 с.

Маслова В.А. Культурно-национальная специфика русской фразеологии [Текст] / В.А.Маслова // Культурные слои во фразеологизмах и в дискурсивных практиках. - М.: Языки славянской культуры, 2004. - С. 69-73.

Словарь архаических слов // https://eksisozluk.com/ici-burkulmak--293219

\section{References}

Babkin A.M. (1977) Idiomatika (frazeologiya) v yazike i slovare [Idiomatics (phraseology) in language and the dictionary] Modern Russian lexicography. Leningrad: p. 4-19 (in Russian)

Binovich L.E. (1995). Nemetsko-ruskiy frazeologicheskiy slovar [German-Russian phraseological dictionary] Moscow: Aquarium, 768 p. (in Russian).

Cheyf W.L. (1975). Znacheniye i struktura yazika [Semantics and structure of language]. Moscow: Progress, 432 p. (in Russian).

Kalitkina Y.N. (2011). Pozitivnioye i negativnoye nachalo v animalisticheskoy charakteristike antroponimov [The positive and negative beginning in animalistic characteristic of antroponyms] University readings. Part VIII. Pyatigorsk. 158 p. P. 25-30. (in Russian).

Mirzaliyeva M. (2009). Teoreticheskiye problemi frazeologii turkskih yazikov [Theoretical problems of phraseology of Turkic languages]. Baku: Nurlan: 296 p. (in Azerbaijani).

Mammadov M.B. (2005). Filologicheskiye misli [Philological thoughts] Baku: Nurlan: 230 p. (in Azerbaijani).

Maslova V.A. (2004) Lingvokulturologiya [Cultural linguistics]. Moscow: Academiya, 208 p. (in Russian)

Maslova V.A. (2004). Kulturno-nasionalnaya spesifika russkoy frazeologii [Cultural-national specifics of the Russian phraseology] Occupation layers in phraseological units and in the diskurs practicians. Moscow: Languages of Slavic culture. P. 69-73. (in Russian).

Royzenson L.I. (1973). Leskii po obshey i russkoy frazeoigii [Lectures on the general and Russian phraseology]. Part I. Samarkand. 290 p. (in Russian)

Solodub Y.P. (1990)/ Nasionalnaya spesifika i universalniye svoystva frazeologii kak obyekt lingvisticheskogo issledovaniya [National specifics and universal properties of phraseology as object of a linguistic research] Philological sciences. Moscow, № 6. P. 35 (in Russian)

Slovar arkhaicheskih slov [Dictionary of archaic words] https://eksisozluk.com/ici-burkulmak--293219 (in Turkish).

Teliya V.N. (1999) Phraseology v kontekste kulturi [Phraseology in the чтения context of culture] Moscow: Languages of Russian culture, 337 p. (in Russian). 